\title{
A JUVENTUDE RUMO À DOCÊNCIA: CONSIDERAÇÕES ACERCA DA FORMAÇÃO PROFISSIONAL EM EDUCAÇÃO FÍSICA
}

\author{
MS. GILSON CRUZ JUNIOR
}

Doutorando em Educação pela Universidade Federal de Santa Catarina (PPGE/UFSC) Professor-tutor do curso de Licenciatura em Educação Física da Universidade Federal do Espírito

Santo (Vitória - Espírito Santo - Brasil)

Laboratório e Observatório de Mídia Esportiva (LABOMÍDIA/CDS/UFSC)

E-mail: gijao05@hotmail.com

\author{
MS. FRANCISCO EDUARDO CAPARRÓZ \\ Doutorando pela Universidade de Barcelona-Espanha \\ Professor adjunto do Centro de Educação Física e Desportos da Universidade Federal do Espírito \\ Santo (Vitória - Espírito Santo - Brasil) \\ E-mail: caparroz.vix@gmail.com
}

\begin{abstract}
RESUMO
Este artigo se insere no campo de debates concernido na formação acadêmico-profissional em Educação Física, em sua interface com o tema juventude, propondo-se a refletir sobre as formas pelas quais esta condição - de jovem - pode exercer influência sobre as significações atribuídas pelos sujeitos em formação inicial ao ser professor. Para alcançar essa meta, organiza-se de acordo com o seguinte itinerário de discussão: a) princípios básicos do fenômeno juventude; b) o atual cenário da educação superior brasileira, à luz de suas relações com o imaginário juvenil; c) nexos dessa conjuntura com a formação docente em Educação Física.
\end{abstract}

PALAVRAS-CHAVE: Juventude; formação profissional; educação fisica. 
No âmbito acadêmico, já é consenso apreender o imperativo da formação profissional do professor como uma demanda que não se restringe somente aos espaços universitários. A responsabilidade de conduzir esse processo recai sobre as instâncias de exercício da docência. É nelas que, de acordo com os desafios trazidos amiúde pelo contexto de intervenção, o professor se depara com a tarefa de fundar novos conhecimentos significativos, na intenção de reinventar os saberes e fazeres de sua ação pedagógica.

Entretanto, ainda que a etapa inicial de formação não seja capaz de condensar todo o conjunto de subsídios preciosos à docência, subvertê-la a um lugar de secundária importância, em relação à formação continuada, significa assumir sérios riscos de mutilar o perfil desse profissional, causando danos severos à sua constituição.

Partimos do entendimento que a preparação acadêmica, reduzida por muitos olhares ao plano da habilitação legal, é um tempo crucial na construção de bases relativas à estrutura identitária docente. Sobre isso, intuímos a necessidade de ressaltar que o tema da identidade figura entre os principais desafios apresentados no horizonte da formação de professores.

Em face às consequências da Modernidade, somos capazes de observar a reconfiguração dos princípios pelos quais essa noção - identidade -, tomada sob o prisma cultural, ganha inteligibilidade. A esse respeito, é indispensável aludir a Hall (2005), quando declara que a fragmentação do sujeito, impacto causado pela nova compreensão acerca dos modos de estruturação e organização da sociedade, é um dos grandes responsáveis por tais transformações. O autor argumenta que

As sociedades da modernidade tardia [...] são caracterizadas pela 'diferença'; elas são atravessadas por diferentes divisões e antagonismos sociais que produzem uma variedade de diferentes 'posições do sujeito' - isto é, identidades - para os indivíduos. Se tais sociedades não se desintegram totalmente não é por que elas são unificadas, mas porque seus diferentes elementos e identidades podem, sob certas circunstâncias, ser conjuntamente articulados (HALL, 2005, p. 17).

No âmbito da educação, um dos corolários desse modo de pensamento pode ser evidenciado no crescente reconhecimento da subjetividade como domínio de composição multidimensional. Por consequência, também é sublinhada a preocupação com as influências que essa condição exerce sobre diferentes processos de natureza formativa. Fatores socioeconômicos, étnicos e ligados ao gênero, são bons exemplos de eixos temáticos até então pouco explorados, que, ao longo das últimas décadas, adquiriram ampla visibilidade no discurso e nas investigações do campo educacional. 
Todavia, no que se refere às investidas sobre o professor e sua respectiva formação, observamos que, particularmente, uma das dimensões de sua personalidade tem sido pouco esmiuçada nesses estudos: a de jovem.

Este ensaio representa uma síntese e, ao mesmo tempo, um prolongamento de algumas questões apresentadas pela pesquisa "Educação Física, Juventude e Sociedade: cenários e desafios da/na formação acadêmico-profissional'" (CRUZJUNIOR, 2009). Nela, discutimos acerca das interfaces existentes entre a noção de juventude e a formação profissional, na tentativa de identificar alguns dos agentes presentes na constituição desse vínculo, juntamente com as suas manifestações específicas no campo da Educação Física. Não obstante, o foco de nossa incursão atual está centrado sob as significações atribuídas pelos jovens ao ser professor, levando em conta alguns dos fatores que interferem nesse processo.

Com a finalidade de explicitar alguns pontos-chave para a compreensão da problemática, dividimos este texto em três momentos distintos: o primeiro traz considerações acerca do conceito de juventude e algumas de suas caracterizações básicas; o segundo aborda aspectos pertinentes à configuração atual da formação acadêmico-profissional no Brasil, enfatizando a posição ocupada pelo jovem neste contexto; e o terceiro, por meio do diálogo com informações de natureza empírica, aponta algumas das inserções da temática na formação docente em Educação Física.

\section{A JUVENTUDE NO PLURAL}

Sem maiores receios, é possível afirmar que os fenômenos circunscritos nos universos juvenis têm atraído olhares de natureza multidisciplinar sobre suas temáticas emergentes, dentre os quais figuram os da História, da Antropologia e da Sociologia. Não obstante, também pesa sobre eles uma apreensão que até então não pôde ser superada: sua imprecisão conceitual.

Muitas tentativas de estabelecer uma definição para essa categoria têm sido gestadas no campo acadêmico, porém, um dos poucos frutos advindos desse debate é a certeza de que a juventude é um objeto de difícil delimitação. Ainda assim, conforme os estudos sobre o tema se multiplicam, torna-se mais fácil a identificação de alguns dos consensos mínimos a esse respeito.

1. Sobre a questão metodológica, é relevante esclarecer que se trata de uma investigação empírica, de caráter exploratório. Nela, a construção dos dados analisados foi conduzida mediante a aplicação de dois instrumentos distintos: questionários compostos de questões fechadas e semiabertas; e de entrevistas semiestruturadas. $\bigcirc$ universo amostral desse estudo se constituiu essencialmente por estudantes finalistas do Curso de Licenciatura em Educação Física do Centro de Educação Física e Desportos (CEFD), da Universidade Federal do Espírito Santo (UFES). 
No entendimento de Peregrino (2004), o jovem é composto, num primeiro viés, por uma espécie de base material, que tem seu fundamento na cronologia concebida como princípio objetivo, pré-social, pré-biológico e físico. Por outro lado, a autora não descarta a ambivalência presente no ser jovem, admitindo que esta suposta materialidade existe numa dada sociedade, que, por sua vez, confere-lhe feições estéticas e valorativas. Logo, defende que o resultado final da interlocução entre o material e o simbólico não pode privilegiar um plano em detrimento do outro. Pelo contrário, apoia a sua indissociabilidade e isonomia.

O composto resultante é o corpo do jovem. Que não é feito 'só' de cronologia, pois, esta, desprovida de expressão valorativa, sem cultura, é materialidade bruta, estatística. Por outro lado, esse corpo não pode ser visto apenas como "livre" expressão de cultura, porque cultura sem 'cronologia' - base material - é vazia; simbolismo autóctone, culturalismo (PEREGRINO, 2004, p. 8).

Na tentativa de sanar esse conflito, Peregrino (2004), com base nas reflexões de Mario Margulis e Marcelo Urresti, ${ }^{2}$ vale-se de um conceito amplamente utilizado em estudos do gênero: a moratória vital. Inscrita na já referida dimensão cronológica da realidade, esta noção se sustenta na premissa de que a juventude é uma fase da vida na qual se dispõe de um excedente temporal, isto é, uma espécie de capital temporal em fartura. Em geral, isso remete à energia e à disponibilidade geralmente esbanjadas pelos sujeitos juvenis nas diversas atividades que caracterizam a sua existência no mundo concreto.

Por outro lado, as possibilidades de gozo das condições de realização e expressão, intrínsecas a essa predisposição natural, estão intimamente ligadas aos lugares sociais ocupados por esses indivíduos. Revestindo a matéria bruta de sentido, o caráter semiológico da Juventude é composto pelo conjunto de diferenças socioculturais existentes entre diferentes segmentos de um dado contexto, que, por sua vez, se distinguem em função de arranjos de classe, e também das ações que promovem em busca da afirmação de seus respectivos modos de ser jovem.

Diante disso, admite-se a compreensão de que a Juventude se configura como um campo de disputa e de poder, do qual emergem hierarquizações, privilégios, centros e periferias. Na qualidade de fenômeno cultural, o jovem tende a espeIhar de maneira relativamente fiel à síntese de suas coordenadas e determinações histórico-sociais.

Ainda em Peregrino (2004), a comparação da moratória vital ao que, na economia política clássica, habituou-se a nomear de valor de uso, nos provoca a

2. Para maiores detalhes, consultar a obra "Juventud es más que una palabra" ( 1996 ). 
indagar sobre: a que ideia equivale, então, o valor de troca, no âmbito dos estudos sobre a Juventude? Na tentativa de contornar esse dilema, a autora lança mão da seguinte definição:

[...] [é] a linguagem social que compatibiliza esta diferença energética num signo (capital simbólico) que permite sua intercambialidade, em uma abstração que permitindo, por sua vez, uma particular distribuição social, por classe, desse capital, em que jogam os interesses do "mercado" (MARGULIS; URRESTI, I996, p. 23, apud PEREGRINO, 2004).

A definição de níveis de fruição e acumulação desse capital simbólico está subordinada a outro tipo de excedente, que não é mais vital, e sim social. Distribuído entre os diversos grupos juvenis por várias entidades e instituições, essa unidade de medida é um elemento essencial na compreensão do processo de estetização e valoração que os jovens sofrem no âmbito da sociabilidade. É neste excedente social, por vezes concebido como o "período dilatado de espera vivido pelos que já não são crianças, mas ainda não se incorporaram à vida adulta" (KEHL, 2004, p. 9I), que se concentram os subsídios que habilitam o jovem a gozar de sua condição inerente: a juventude. Tal excedente também pode ser chamado de moratória social.

Tais princípios contrariam a noção de que, para ser jovem, basta apenas corresponder a um enquadramento etário específico, isto é, acomodar-se num recorte de idade. Ao recobrir-se de sentido no espaço social, o capital energético (a moratória vital) adquire outro formato, em função do tempo de espera do qual dispõe o indivíduo, na transição e no usufruto implicados na moratória social. Isso significa que não há como analisar os mecanismos de produção da(s) juventude(s) de modo consistente, sem antes lançar um olhar atento às estruturas e aos sistemas que compõem o mundo de relações interpessoais e institucionais da sociedade em evidência.

Em Dayrell e Gomes (2009), encontramos uma leitura pertinente, que nos permite avançar na ponderação sobre esta categoria. Nesta ocasião, os autores apresentam a noção de juventude como segmento circunscrito numa dupla face: de termo genérico, utilizado para designar indivíduos inseridos num determinado recorte etário; ${ }^{3}$ e de condição social, que se revela de modos variados, de acordo com as coordenadas históricas, culturais, econômicas e políticas, sobre as quais repousa.

É necessário enfatizar que esta última dimensão é o que torna a análise do fenômeno juventude tão complexa, dado que este processo de apreciação não

3. Em geral, demarcada dos 15 aos 24 anos. De qualquer maneira, não existem grandes consensos sobre esta delimitação, pois, de maneira gradual, ela parece se expandir, em conformidade com as novas investigações que surgem sobre a temática. Alguns estudiosos do tema chegam a trabalhar com recortes que têm início aos 12 e chegam aos 30 anos de idade. 
pode se valer (somente) de especificações conceituais de caráter genérico, devendo também recorrer aos indícios de natureza circunstancial que envolvem o objeto.

Novaes (2007), atenta ao conflito latente na ideia de juventude, opta por conceituá-la como

[...] um tempo de construçãa de identidades e de definição de projetos de futuro. Por isto mesmo, de maneira geral, a juventude é a fase da vida mais marcada por ambivalências. Ser jovem é viver uma contraditória convivência entre a subordinação à família e à sociedade e ao mesmo tempo, grandes expectativas de emancipação (NOVAES, 2007, p. I).

Talvez, por essa razão, a juventude teima em ser encarada como uma fase da vida fundamentalmente transicional. Nessa perspectiva, o jovem é um indivíduo que caminha na direção da maioridade, e para isso, deve responder às demandas, aos códigos e às incumbências, social e historicamente legadas pela civilização, no intento de ascender ao status de adulto.

Quanto a isso, é pertinente alertar que a leitura do objeto juventude através desse tipo de lente pode se revelar reduzida, simplista, fragmentada. Olhares como este tendem a conceber o jovem como um indivíduo que "ainda não é", mas que, num determinado momento, "será". Ao operar dessa maneira, tal perspectiva nega a sua capacidade juvenil de intervir de maneira significativa no presente, ou seja, de constituir a si mesmo(a) enquanto sujeito/categoria e a sua realidade, transformando-a. Sendo assim, entendemos que o exame do conjunto de iniciativas e lógicas de ação próprias ao imaginário e às práticas juvenis, demanda também a consciência e compreensão acerca dos diferentes papéis que este segmento vem cumprindo desde já, em todos planos da vida social.

\section{O JOVEM E O ENSINO SUPERIOR}

De antemão, reconhecemos a complexidade inerente à tarefa de precisar as funções que atualmente têm sido cumpridas pela universidade, no que tange às suas interfaces com o restante do mundo social. Basicamente, isso se deve às profundas reconfigurações que têm modificado suas finalidades primeiras, processo esse instigado por uma série de transformações intensas testemunhadas nas últimas décadas nos âmbitos político, econômico e social.

Se até determinado momento da história prevaleceu a certeza de que essa instituição mantinha objetivos centrados unicamente na produção do conhecimento "para si mesma", isto é, sem o compromisso de atribuir a eles algum tipo de utilidade ou aplicação técnica, hoje, temos fortes indícios de que a universidade tem se tornado cada vez mais solícita às necessidades situadas para além de seus domínios físicos 
e simbólicos - com destaque para as exigências oriundas dos setores produtivos.

Provável protagonista dessa mudança, a intensificação da demanda por mão-de-obra qualificada, efeito da proliferação da oferta de postos de trabalho, incitou um profundo processo de reestruturação social. $\bigcirc$ movimento de industrialização, que já no século XIX se fez realidade em países europeus, no Brasil teve início somente na primeira metade do século $X X$. Não obstante, sob este pano de fundo, o conjunto de ações, medidas e políticas públicas que adquiriram caráter proeminente na criação das condições necessárias para acomodar a nova ordem em trânsito, põe em sua vanguarda a educação, incumbindo-a de garantir a oferta abundante de recursos humanos por intermédio de diferentes tipos de qualificação.

Sguissardi (2008), ao discutir sobre os modelos de expansão aplicados na educação superior brasileira da década de 1970 aos anos 2000, constata o crescimento acentuado na soma de instituições de ensino de caráter privado, em especial daquelas que detêm fins lucrativos. Segundo ele, os mecanismos de regulação incorporados pelo estado no decorrer desse período demonstram a prevalência de interesses notadamente mercadológicos, no que tange à organização do subsistema educacional universitário. Diante desse cenário, o autor se questiona a respeito do futuro do ensino superior brasileiro e mundial, temendo a sua descaracterização enquanto instância de produção de saber e de formação de profissionais qualificados e cidadãos críticos.

Desde as décadas de 1970 e 1980, a profissionalização deixou de se caracterizar apenas como um elemento secundário na identidade do indivíduo, adquirindo cada vez mais o status de fundamento estruturante na constituição do trabalhador hodierno. Concomitantemente, os processos de formação e capacitação calcados nessa perspectiva têm assumido o caráter de imperativo, consolidando-se como condição sine qua non para a inserção nos campos e postos de trabalho existentes até então. Nesse caso, o desemprego não corresponde mais unicamente a uma consequência natural da ausência de vagas em determinados ramos dos setores produtivos, configurando-se, igualmente, como a resposta mais comum dada àqueles que estão destituídos das prerrogativas trazidas pela formação profissional.

De acordo com informações obtidas por intermédio do Projeto Juventude, ${ }^{4}$ as categorias trabalho e emprego figuram entre os maiores interesses presentes no imaginário dos jovens brasileiros. Superados apenas pela violência nessa hierarquia, os temas pertinentes à profissão, no geral, são encarados como grandes desafios

4. Iniciativa da Fundação Perseu Abramo, em parceria com o Instituto Cidadania e o Governo Federal, teve como finalidade promover estudos e pesquisas com a finalidade de traçar um perfil do jovem brasileiro, entendendo suas inserções nas esferas política, educacional e cultural. 
no horizonte desse segmento. Ademais, com base nos dados apresentados pelo Dossiê Universo Jovem (MTV, 2008), investigação promovida pela rede de TVMTV, verificamos que uma das principais origens dessa preocupação é a dificuldade de ingressar no mercado de trabalho. Em face dessa constatação, a pesquisa enfatiza que os jovens

[... ] sentem na pele a alta taxa de desemprego e são cientes dos principais fatores de sucesso no momento de concorrer no mercado: ter boa formação educacional (73\%), ter cursos de especialização, pós/MBA (46\%) e estar bem informado (40\%) (MTV, 2008, p. I I).

Com o acirramento da competição nos mercados de trabalho, o jovem é convocado a ratificar cada vez mais cedo as suas inclinações, preferências e possibilidades de exercício profissional. Esse é o cenário no qual o jovem tende a dar centralidade às vantagens oferecidas pela escolarização e pela profissionalização, encarando-as como recursos estratégicos, cuja função é garantir as condições objetivas para subsidiar seus projetos para o futuro.

É conveniente esclarecer que tais oportunidades de formação têm a moratória social como seu maior princípio regulador, uma vez que é ela o que as torna passíveis de fruição, em maior ou menor grau, de acordo com seus determinantes culturais, políticos, econômicos e ideológicos. Uma das formas de ilustrar essa relação é por intermédio da sina com a qual sofre boa parte dos jovens das classes menos abastadas: estes, em relação àqueles que provêm de estratos socioeconômicos mais "favorecidos", sofrem com vários tipos de restrição e obstáculos em seus percursos formativos, sejam eles de natureza escolar ou acadêmica. Com isso, estão reduzidas também as suas chances de alcançar os níveis de ensino que extrapolam a educação básica.

Por outro lado, a chamada profissionalização precoce, fenômeno que tem atingido os jovens oriundos de todas as classes, tem causado uma série de problemas no que diz respeito ao(s) propósito(s) atribuído(s) à busca de capital cultural. Atento à forte base pragmática introduzida no seio da formação universitária no decorrer das últimas décadas, Nunes (2006) denuncia o reducionismo que vem sendo gestado no pensamento de adultos, de jovens e até mesmo de crianças, em relação ao papel assumido pelo conhecimento acadêmico nos âmbitos individual e social da vida civilizada. Ele alega que

[... desde o ensino médio, pelo menos, inicia-se um processo de restrição da "visão de mundo" das gerações futuras, tornando-as candidatas à profissão antes de serem candidatas ao saber. Ao ingressarem nas instituições de ensino superior, tendo vindo, em geral, de um ensino médio decepcionante, salvo as exceções da elite de praxe, nossos estudantes orientam-se por uma matriz profissionalizante de ensino, deixando de lado a formação mais abrangente, humanística, histórica e social... Enfim a educação (NUNES, 2006, p. 4). 
Em que pese o alcance e a profundidade dessa tendência, as discussões sobre o binômio juventude-trabalho não podem negligenciar um componente essencial do fenômeno: o caráter estético da profissão. Se em determinado momento, o exercício profissional é percebido somente como um meio de garantir as condições materiais de existência do indivíduo, hoje, essa apropriação se amplia, passando a incorporar funções de natureza simbólica. Ter o que comer, vestir e onde morar, não é mais o fator preponderante nesse tipo de empreitada. Eis que entra em cena a ânsia de consumar aspirações pessoais, erigidas de acordo com disposições culturais complexas e heterogêneas.

Com a ampliação de seus níveis de autonomia, o jovem tem nas mãos o poder e a responsabilidade pelas decisões tomadas em relação a seus diferentes contextos de inserção. Nesse momento, suas escolhas tendem a não ser mais (apenas) um reflexo direto dos desígnios da família ou da escola, e cujos direcionamentos reproduziam fielmente as intencionalidades extrínsecas a esse sujeito. Ainda que, por intermédio de inúmeros jogos e relações de poder, tais instituições tenham condições de afetar os referidos processos de decisão, o jovem parece, acima de tudo, buscar a afirmação e legitimação de sua individualidade, mesmo que não tenha sucesso em se desvencilhar inteiramente destes e de outros tipos de interdição.

\section{O JOVEM, A DOCÊNCIA E A EDUCAÇÃO FÍSICA}

Visando delinear as inserções do fenômeno juventude no contexto da formação acadêmico-profissional em Educação Física, optamos, num primeiro momento, por enfatizar os determinantes de natureza socioeconômica envolvidos nessa trama, recorrendo a informações obtidas através de pesquisa empírica. Para tanto, investigamos sobre a origem dos jovens pesquisados, mais especificamente, acerca de suas respectivas classes sociais, ponderando sobre os possíveis elementos agenciadores de sua relação com a área, realçando alguns dos interesses, dos conflitos e das contradições presentes neste vínculo.

Os resultados obtidos indicam o predomínio de indivíduos pertencentes às classes A I, A2, B I, B2 e CI. 5 Tal recorte compreende fundamentalmente as classes média e alta. Uma das explicações para esse quadro se baseia no papel discriminatório cumprido pelas universidades (públicas) no país. Dotada de instrumentos seletivos altamente meritocráticos, essa instituição tem agido como mecanismo de exclusão, que evidencia inúmeras debilidades presentes na educação básica estatal, deixando

5. De acordo com os Critérios de Classificação Econômica Brasil (CCEB), da Associação Brasileira de Empresas de Pesquisa (ABEP). 
à margem dos processos de produção e socialização do conhecimento elaborado, os grupos sociais impedidos (financeiramente) de acessar meios de escolarização mais "competitivos" nesse tipo de certame.

Embora cerrada por essa e outras formas de "triagem", mediante as quais se impõem barreiras ao ingresso e à permanência de determinados segmentos em seus domínios, a universidade ainda possui algumas fissuras em sua espessa couraça. Os cursos de licenciatura são emblemáticos a esse respeito, uma vez que, por intermédio deles, somos capazes visualizar as divisões internas presentes no campo universitário, cujo acirramento influi direta e indiretamente na criação das brechas anunciadas.

Antes de tornar essa relação explícita, é conveniente enfatizar que a educação superior tem atuado como dispositivo (re)afirmador das hierarquias entre classes. Sustentada pelo descompasso presente na distribuição institucional da cultura, esse nível de formação tem cumprido um papel estratégico nos processos de manutenção e ascensão social. Quanto a isso, as ideias de "ascensão" e "manutenção" também carecem de relativização, esforço que deve concebê-las enquanto representações decorrentes do conjunto de determinações socioeconômicas próprias à realidade de cada jovem.

Ao antecipar os predicados vinculados às suas respectivas carreiras, os cursos de graduação são imbuídos de toda a carga de significações invocada pelos cargos e funções para os quais preparam. Em relação às licenciaturas, essa dinâmica tem se mostrado ainda mais implacável, inteirando os futuros professores do atual estado de proletarização que aflige a sua categoria (NÓVOA, 1995). Em seus estudos sobre o abandono do magistério, Lapo e Bueno (2003) apontam algumas das razões que contribuem com esse quadro: a) a baixa remuneração; b) condições de trabalho insatisfatórias; c) horizonte restrito de ascensão profissional; d) o "desencanto" com a profissão.

Encaradas sob o signo da desvalorização social e financeira, as licenciaturas têm amargado as últimas posições nas listas de cursos mais procurados das universidades. Consideramos que tal ocorrência é sintomática, por sugerir que esse ramo de atuação não figura entre as preferências dos jovens pertencentes às classes altas, já que, em comparação às carreiras de prestigio notório - tais como a Medicina, o Direito e a Engenharia -, esta habilitação costuma não se alinhar às intenções de manutenção e ascensão social típicas a esse segmento. A despeito disso, as licenciaturas também representam a saída mais conveniente para aqueles que, em razão das condições objetivas limitadas, dificilmente terão a oportunidade de ingressar em instituições de ensino superior (públicas). Diante disso, como explicar a contradição existente entre o perfil socioeconômico dos estudantes de Educação 
Física - composto essencialmente por jovens de classe média e alta - e a já esboçada tendência dos cursos licenciatura?

Nesse sentido, Figueiredo (200 I) ressalta o valor das experiências sociocorporais que antecedem o ingresso do indivíduo no curso de formação, no processo de escolha da profissão. No caso da Educação Física, a autora assinala a identificação estabelecida pelo sujeito com algum dos conteúdos da área (a dança, o esporte, as lutas e etc.) como elemento decisivo na predileção dos jovens investigados por este curso.

Não obstante, ao questionar os sujeitos da pesquisa sobre a natureza dessas experiências, isto é, sobre o tipo de afinidade prévia que estabeleceram com o universo da cultura corporal, identificamos um extenso mosaico de práticas, cuja constituição se revelou plural e heterogênea sob o ponto de vista da especialidade, com destaque para as vivências proporcionadas por academias de ginástica e musculação, clubes e associações esportivas, assim como projetos sociais. Tal informação insinua a não-centralidade das vivências proporcionadas pelos espaços escolares, contrariando as conjecturas mais esperadas num curso de licenciatura.

No debate acerca do universo de legitimação da Educação Física como componente curricular, Bracht (200 I) faz referência à proliferação dos contextos de intervenção sob a responsabilidade da área, relacionando-a à crescente penetração do ideário neoliberal no bojo das políticas externa e interna do país. O autor afirma que, com a diminuição paulatina da responsabilidade em gestar políticas calcadas no bem estar social, o Estado vem transferindo à iniciativa privada a responsabilidade de elaborar e implementar propostas e ações específicas direcionadas aos setores da saúde, segurança e educação. Com isso, torna-se mais intensa e explícita a conformação das práticas corporais aos escopos de natureza mercadológica, convertendo-as num largo rol de produtos e serviços.

Chegamos a um ponto crucial da discussão, que alude a uma categoria-chave entranhada no imaginário e nas atitudes juvenis da contemporaneidade: o consumo. Kehl (2004), ao discorrer sobre a gênese da juventude enquanto fruto da cultura, sinaliza a interferência decisiva da indústria cultural nos processos de produção e difusão dos códigos, padrões de conduta e até mesmo das próprias identidades desta categoria. Ao notar o potencial nicho de mercado adormecido num grupo que alia "[...] o tédio, a insatisfação sexual sob alta pressão hormonal, a dependência em relação à família e a falta de funções no espaço público [...]" (KEHL, 2004, p. 91), as agências signatárias do sistema capitalista não tardaram em criar um vasto conjunto de representações do ser jovem, sustentadas por inúmeros objetos, comportamentos e valores, astutamente associados às mercadorias forjadas por essas mesmas entidades. 
Desse modo, subentende-se que a conformidade criada entre o jovem professor em formação e a Educação Física - entendida como campo acadêmico e de intervenção - deve-se, em boa medida, aos contatos que os indivíduos deste grupo têm com determinadas práticas corporais mercantilizadas. Este encontro é incitado por sua vontade de se fazer sujeito, e de agregar à sua personalidade novos traços que, nesse caso, são logrados de acordo com a lógica vigente na sociedade dos consumidores. Tal fato também justifica a proeminência adquirida pela dimensão remunerativa da profissão, posto que nela estão expressas as possibilidades de construção identitária, por meio da interação com um vasto universo de mercadorias.

Ainda assim, Ribeiro (2004) afirma a condição de ambivalência que afeta os jovens do século $X X \mid$, apelando para a metáfora cunhada pelo cineasta francês Jean Luc Godard, que consiste na ideia de que estes indivíduos são, ao mesmo tempo, filhos de Karl Marx e da Coca-Cola. Ao fazer uso dessa figura, o autor reconhece que, mesmo entregue aos ícones da cultura consumista, a juventude também se revela permeável aos ideais e inclinações de cunho revolucionário.

No tocante à formação acadêmica em Educação Física, mesmo que de maneira tímida, os porta-vozes da contracultura também estão representados. Nesse caso, referimo-nos aos jovens que concebem a intervenção pedagógica como um importante instrumento a serviço da criação e transformação da realidade. Ainda que de maneira ingênua e idealizada, esses sujeitos nutrem a crença de que a escola é um espaço de luta, investida do potencial de livrar a humanidade das mazelas que a aflige, valendo-se da transmissão cultural igualitária, por meio da qual procura formar indivíduos críticos, autônomos e eticamente competentes.

A fé depositada pelos jovens no esporte, mais precisamente, na sua capacidade de reduzir o fosso de desigualdade que separa diferentes grupos sociais, revela que essa vontade de mudança está articulada à compreensão que esse indivíduo tem acerca da tarefa confiada à Educação Física, no cerne dos projetos pedagógicos de caráter crítico e progressista. Ainda que baseada em lugares comuns, há muito desmistificados pela produção intelectual do campo, as leituras românticas acerca do desporto acenam como vias de acesso ao imaginário juvenil, que permitem a identificação e complexificação de seus saberes e representações acerca do ser professor, e favorecem o amadurecimento de sua consciência acerca da dimensão político-ideológica da docência.

\section{CONSIDERAÇÕES FINAIS}

Dentre as conclusões permitidas, está a certeza de que não esgotamos a discussão pertinente ao trinômio composto por juventude, formação profissional e 
Educação Física. Pelo contrário, ressaltamos que o intuito deste trabalho foi justamente acionar a problemática, por meio da apresentação de alguns de seus aspectos constitutivos, visando sensibilizar o leitor acerca de sua relevância para os estudos que buscam abranger os agentes implicados na composição do ser professor.

Para tanto, é essencial dar visibilidade aos fatores subjetivos socioculturais que exercem influência sobre a estrutura identitária docente, no sentido de revelar suas consonâncias, seus conflitos e suas contradições. Como categoria de análise, a juventude representa uma via profícua de reflexão acerca dos aspectos antropológicos, históricos, psicológicos e sociológicos, imbricados na personalidade do professor em formação. Se levada a sério, essa demanda pode render valiosas contribuições a diferentes tipos de projeto pedagógico, sejam eles ou não do ensino superior. Imbuindo-os dos saberes concernentes ao jovem e a seus elementos periféricos, os processos de ensino-aprendizagem são capazes de estabelecer novas linguagens, conhecimentos e recursos, que permitirão potencializar o diálogo entre currículo e indivíduo em formação, desestabilizando a noção genérica de sujeito que perdura em sua matriz.

Por fim, é importante frisar ainda que os agentes inseridos nesse estágio da vida investem parcela considerável de suas forças na busca de parcerias, ideias e atividades, que possam refletir e ao mesmo tempo cativar suas respectivas individualidades. Diante disso, no tocante à formação docente, o desafio maior consiste em formular e implementar ações estratégicas capazes de reduzir a centralidade atribuída pelo jovem ao consumo nas iniciativas dessa natureza, já que esse tipo de racionalidade é antagônica aos processos formativos de natureza emancipatória. Ao se desvencilharem inteira ou mesmo parcialmente dos interesses ideológicos mercantis, os jovens também instrumentalizam-se para a tarefa de compor as várias facetas de sua autoimagem, munindo-se da autonomia, do esclarecimento e do senso ético imprescindíveis a tal feito.

\section{Youth on the Path of Magistry: Considerations about the Professional Training in Physical Education}

ABSTRACT: This article falls within the debates linked to academic and professional training in Physical Education, at its interface with the theme of youth, intending to reflect on the ways in which this condition - youth - may influence the meanings attributed, by subjects in initial training, to the be teacher. To achieve this goal, we established the following itinerary for discussion: a) basic principles of youth phenomenon; b) current situation of Brazilian higher education and its relations with the juvenile imaginary; c) links between this situation and the teacher training in Physical Education.

KEYWORDS: Youth; professional training; physical education. 


\section{La juventud rumbo a la enseñanza: consideraciones acerca de la formación profesional en educación física}

RESUMEN: Este artículo se inscribe en los debates vinculados a la formación académica y profesional en Educación Física, en su interfaz con el tema de la Juventud, con la intención de reflexionar sobre las formas en que esta condición - los jóvenes - pueden influir en los significados atribuidos, por los sujetos en la formación inicial, al ser maestro. Para lograr este objetivo, se estableció el siguiente itinerario para el debate: a) principios básicos del fenómeno juvenil, b) la situación actual de la educación superior en Brasil, a la luz de sus relaciones con el imaginario juvenil, c) los eslabones de esta coyuntura con la formación del profesorado en Educación Física.

PALABRAS CLAVE: Juventud; formación Profesional; educación física.

\section{REFERÊNCIAS}

ABRAMO, H. W.; BRANCO, P. P. M. (Org.). Retratos da juventude brasileira: análises de uma pesquisa nacional. São Paulo: Fundação Perseu Abramo, 2008.

BRACHT, V. Saber e fazer pedagógicos: acerca da legitimidade da Educação Física como componente curricular. In: CAPARROZ, F. E. Educação Física Escolar: política, investigação e intervenção. Vitória: Proteoria, 2001.

CRUZJUNIOR, G. Educação Física, juventude e sociedade: cenário e desafios da/na formação acadêmico-profissional. 2009 Trabalho de Conclusão de Curso - Universidade Federal do Espírito Santo, 2009.

DAYRELL, J. T.; GOMES, N. L. A juventude no Brasil. Disponível em: <http://www.cmpbh. com.br/arq_Artigos/SESI\%20JUVENTUDE\%20NO\%20BRASIL.pdf>. Acesso em: I 5 jun. 2009.

FIGUEIREDO, Z. C. C. Formação docente, currículo e saber. In: CAPARROZ, F. E. Educação Física escolar: política, investigação e intervenção. Vitória: Proteoria, 2001 .

HALL, S. Identidade cultural na pós-modernidade. Rio de Jan: DP\&A, 2005.

KEHL, M. R. A Juventude como sintoma da cultura. In: NOVAES, R.; VANNUCHI, P. (Org.). Juventude e sociedade: trabalho, educação, cultura e participação. São Paulo: Perseu Abramo, 2004. p. 89-।|4.

LAPO, F. R.; BUENO, B. O. Professores, desencanto com a profissão e abandono do magistério. Cadernos de Pesquisa, São Paulo, n. I 18, p. 65-88, mar. 2003.

NUNES, E. Ensino universitário, corporação e profissão: paradoxos e dilemas estratégicos do Brasil. Observatório Universitário, 2006. Disponível em: <http://www.databrasil.org.br/ Databrasil/..\%5Cpdf_docs\%5CDoctrab55.pdf>. Acesso em: I I jun. 2009. 
MTV BRASIL. Dossiê universo jovem 3. Disponível em: <www.mtv.com.br>. Acesso em: 23 jul. 2008

NOVAES, R. Juventude e sociedade : jogos de espelhos, sentimentos, percepções e demandas por direitos e políticas públicas. Revista Sociologia Especial: ciência e vida, São Paulo, 2007.

NÓvOA, A. O passado e o presente dos professores. In: NÓVOA, A. (Org.). Profissão professor. Porto: Porto Editora, 1995.

PEREGRINO, M. A fecundidade da noção de moratória (vital/social) para análise das relações entre juventude e educação no contexto de massificação dos processos educativos. In: REUNIÃO DA ASSOCIAÇÃO NACIONAL DE PÓS-GRADUAÇÃO E PESQUISA EM EDUCAÇÃO, 27., Caxambú, 2004. Anais... Caxambu: Anped, 2004.

RIBEIRO, R. J. Política e juventude: o que fica de energia. In: NOVAES, R.; VANNUCHI, P. (Org.). Juventude e sociedade: trabalho, educação, cultura e participação. São Paulo: Perseu Abramo, p. 19-33, 2004.

SGUISSARDI, V. Modelo de expansão da educação superior no Brasil: predomínio privado/ mercantil e desafios para a regulação e a formação universitária. Revista Educação \& Sociedade, Campinas, v. 29, n. 105, p. 991-1022, set./dez. 2008.

Recebido em: 31 out. 2010 Aprovado em: 14 mar. 2011

Endereço para correspondência:

Gilson Cruz Junior

Av. Saturnino Rangel Mauro, 90c

Praia de Itaparica, Vila Velha, Espírito Santo

CEP: 29102-030

E-mail:gijao05@hotmail.com 